\title{
Towards Developing Communication Strategies for HIV/AIDS Control among the Scheduled Tribes and Scheduled Castes Women in Three Northeastern States of India
}

\author{
Kalyan B. Saha ${ }^{1}$, Damodar Sahu ${ }^{2}$, Uma C. Saha ${ }^{3}$, Ravendra K. Sharma ${ }^{1}$, M. Muniyandi ${ }^{1}$, \\ Prabhaker Mishra $^{4}$, Chhanda Mallick ${ }^{5}$, Jyotirmoy Roy ${ }^{1}$, Amal K. Bhunia ${ }^{6}$, \\ Samiran Bisai ${ }^{1}$, Arvind Pandey ${ }^{2}$
}

${ }^{1}$ Regional Medical Research Centre for Tribals (ICMR), Jabalpur, India; ${ }^{2}$ National Institute of Medical Statistics (ICMR), New Delhi, India; ${ }^{3}$ Xavier Institute of Development, Action \& Studies (XIDAS), Jabalpur, India; ${ }^{4}$ Department of Community Medicine, M. M. Institute of Medical Sciences and Research, Ambala, India; ${ }^{5}$ Department of Biomedical Laboratory Science \& Management, Vidyasagar University, Midnapore, India; ${ }^{6}$ Department of Anthropology, Vidyasagar University, Midnapore, India.

Email: sbisai@hotmail.com

Received November $1^{\text {st }}, 2013$; revised December $1^{\text {st }}, 2013$; accepted December $8^{\text {th }}, 2013$

Copyright (C) 2013 Kalyan B. Saha et al. This is an open access article distributed under the Creative Commons Attribution License, which permits unrestricted use, distribution, and reproduction in any medium, provided the original work is properly cited.

\begin{abstract}
HIV/AIDS spread has opened a Pandora of medical and health problems apart from creating serious socio-psychological trauma for the victims and their families. Despite the governmental effort to curve the growing infection, very little success has been achieved. The northeastern region of India presents a very peculiar situation due to recurrent insurgency in all its states for long time and thus it became instrumental in paralyzing the social and health machineries to an extent, which still deteriorated the futile national effort to check the deadly infection. The study tried to understand the level of awareness and correct knowledge among the underprivileged scheduled tribes and scheduled castes women in the age group 15 - 44 by exploring data from district level of Rapid Household Reproductive and Child Health Project Phase I (1998) and Phase II (1999) for Assam, Manipur and Nagaland and suggested a strategy to control the infection in the region. It is found that HIV/AIDS awareness was 59\% among the women in all the three states with very few among them who had correct understanding of its prevention. A pronounced difference in the level of awareness was observed with respect to age, economy and residential status of the respondents.
\end{abstract}

Keywords: AIDS Awareness; Transmission; Prevention \& Misconception; Communication Strategy

\section{Introduction}

1) The alarming spread of HIV/AIDS is a serious concern for the nation. HIV is thought to have entered India in the early 1980s, but only in March 1986 the first case of HIV infection was detected [1]. However, the initial response of the nation to AIDS was to hide behind the mantle of Indian morals. After acknowledging the problem seriously in early 1990s, efforts are made to treat the diseases victims and prevent further infection but they have been hampered by a lack of reliable data and a glut of ill-conceived or under-funded programmes.

2) According to the National Intelligence Council report of September 2002, HIV infection in India is likely to go up to 20 - 25 million by 2015 . The estimated number of people living with HIV/AIDS in India during 2006 was 2 million - 3.1 million [2]. Northeastern region of India poses a serious matter of concern. The officially reported AIDS cases in the three states of northeast India i.e., Assam (372), Manipur (2866) and Nagaland (736) together are comprised of the highest number of AIDS cases in the region [3]. The characteristics of having porous borders, infested with drug trafficking, flourishing call girl market, insurgency and unrest related syndromes have pushed northeastern India into the AIDS epidemic. However, these figures may not represent the exact situation due to under-reporting of AIDS cases. Experts believe that these cases represent only a small portion of 
actual cases of AIDS in the region. But it definitely indicates the gravity of the problem. In spite of such seriousness of the problem in an orthodox Indian society, an average person in the street seems to be unconcerned and is not willing to discuss the consequences of unprotected sex, one of the major vehicle for the spread of HIV/AIDS.

3) What is currently very disturbing is the growing proportion of women specifically married women infected with HIV. It is predicted that over 15,000 women become infected with HIV every week [4]. Women in India being the vulnerable group are more prone to any type of STDs because majority of them are illiterate and have a low social status, and they are also tied to the four walls of the kitchen, managing other household cores and satisfying the sexual drives of their male counter part. She has no right on her own body and freedom for exercising her willingness and choice [5]. The situation is more disadvantageous among the Scheduled Tribes and Scheduled Castes women who compose a sizeable proportion of the country's population and rest in the bottom of the social hierarchy with poor quality of life and thus signal a potential risk group for the society and need immediate intervention to protect them.

4) Now the big question is how the infection can be prevented? In the absence of any vaccine, education through communication is imperative for influencing personal behaviour and lifestyles to minimize the ravages of AIDS throughout our population [6]. Despite the national commitment towards communication of HIV/ AIDS related messages, not much has been achieved so far. Adequate resources have been allocated, STD clinics have been set up and distribution of free condoms has been taken up albeit with limited success. Furthermore, the entire northeastern India is under the grip of recurrent insurgency of one form or the other for long, and it paralyzes the medical set-up and social life to such an extent, which aggravates the above situation neutralizing the nation's fight against HIV/AIDS completely.

5) In this paper, an attempt has been made to study the level of awareness of HIV/AIDS among the currently married women of the state of Assam, Manipur and Nagaland and suggest a broad communication strategy for controlling the infection in northeastern India.

\section{Methods and Materials}

The data for the present paper has been drawn from a large scale Rapid Household Reproductive and Child Health Survey conducted during 1998-1999 and sponsored by the Ministry of Health and Family Welfare, Government of India. The new approach requires decentralization of planning, monitoring and evaluation of the services at the basic nucleus level, which is district. Thus government of India for the first time felt the need and generated district level basic data on utilization of services provided by Government health facilities and people's perception on quality of these services. The survey also accumulated data on people's awareness and perception on HIV/AIDS infection in the country. In a district, 1100 Households in 50 locations and all currently married women in the age group 15 - 44 years available in the households were covered. Regarding details of sampling design refer to Rapid Household Survey RCH project reports Phase-I and II for Assam, Manipur and Nagaland (Figure 1). For the present study three states out of seven sister states of northeastern India viz., Assam, Manipur and Nagaland were selected purposively, together which comprises of highest number of AIDS cases in the region.

Altogether data have been collected from 38 districts in the above three states. The data were collected by specially trained investigators locally recruited and trained for this purpose. The survey covered 13,141 women in Assam [7], 4658 in Manipur [8] and 6779 in Nagaland [9]. From the total a sample of 24,578 respondents, 16,739 Scheduled Castes and Scheduled Tribes respondents from the three states were extracted for the present study. Generally speaking scheduled tribes and scheduled castes refer to backward section of the society and are identified and mentioned in the scheduled list of the Indian Constitution to extend national privileges for their development. Besides bivariate analysis, multivariate logistic regression analysis has been attempted to understand the controlled effect of the predictor variables on the dependent variables viz., 1) ever heard of HIV/AIDS and 2) ever use of condom.

In the analysis an attempt was made to highlight the

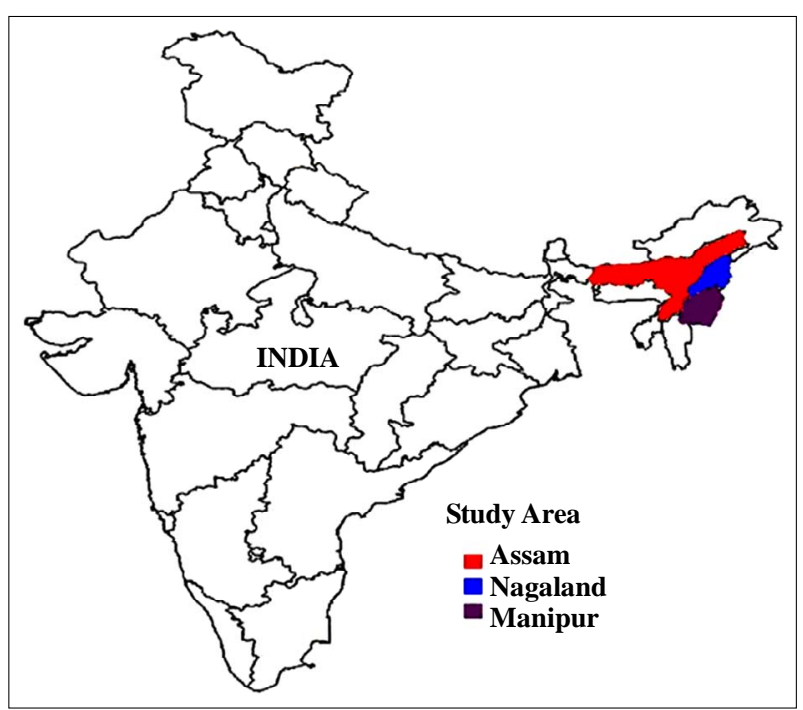

Figure 1. The study area. 
current level of information about HIV/AIDS amongst these respondents and check for differences if any, by religion, age and education, type of house of the women which act as a proxy variable in understanding the effect of economic background of the women. "Puccha" house refers to better economic group while "Kaccha" house signifies a poor economy. Analysis also seeks their sources of information about HIV/AIDS, knowledge about the route of transmission and methods of prevention of HIV/AIDS. These variables are based on multiple responses and were asked only to those who were heard/ aware of HIV/AIDS. The existing misconceptions about HIV/AIDS have been included. The results of the present study are supplemented with facts from other studies in different occasions.

\section{Results and Discussion}

\subsection{Respondents Characteristics}

Scheduled Tribes dominate the sample. Scheduled Castes presence in the sample in all three states put together is little over $43 \%$. About $64 \%$ respondents are Christians, $35 \%$ are Hindus and the remaining one $\%$ belongs to other religion (Table 1).

About $42 \%$ respondents are illiterate and the remaining is literate with education ranging from standard I to $\mathrm{X}$ and above. The literacy rate, it seems, in the three states taken together is much above the national female literacy rate, that too among younger age groups and signals a positive step in the endeavor to curve the spread of deadly infection (Table 2).

Majority of the women live in kaccha houses (64\%) followed by semi-pucca houses (29\%) (Table 3). Regarding interstate variation Assam women reflects relative poverty as compared to those in Nagaland and Manipur.

Table 1. Distribution of scheduled tribes and scheduled castes women by age and religion.

\begin{tabular}{ccccc}
\hline \multirow{2}{*}{ Age groups } & \multicolumn{3}{c}{ Religion } & \multirow{2}{*}{ Total } \\
\cline { 2 - 4 } & Christian & Hindu & Others $^{*}$ & \\
\hline $15-19$ & 1.9 & 2.8 & 2.0 & 2.2 \\
$20-29$ & 35.6 & 37.7 & 34.2 & 36.3 \\
$30-39$ & 39.5 & 42.8 & 39.7 & 40.6 \\
$40-49$ & 23.0 & 16.7 & 24.1 & 20.8 \\
& 10725 & 5815 & 199 & 16739 \\
Total & $(64.1)$ & $(34.7)$ & $(1.2)$ & $(100.0)$ \\
& $(100.0)$ & $(100.0)$ & $(100.0)$ & $(100.0)$ \\
\hline
\end{tabular}

*include Muslim, Buddhist, Sikh, etc.

\subsection{Age at Cohabitation}

According to Table 4 married women reported an early sexual experience with first cohabitation below or around 15 years $(8 \%)$.

However, $48 \%$ have reported having first sexual experience at 20 years of age. Differences have been ob-

Table 2. Distribution of scheduled tribes and scheduled castes women by age and education.

\begin{tabular}{cccccc}
\hline \multirow{2}{*}{$\begin{array}{c}\text { Age } \\
\text { groups }\end{array}$} & \multicolumn{4}{c}{ Education } & Total \\
\cline { 2 - 5 } & Illiterate & Class I-V & Class VI-IX & Class X+ & \\
\hline $15-19$ & 28.9 & 16.5 & 38.4 & 16.2 & $370(100.0)$ \\
$20-29$ & 31.5 & 11.5 & 28.2 & 28.8 & $6080(100.0)$ \\
$30-39$ & 43.7 & 13.2 & 22.4 & 20.7 & $6802(100.0)$ \\
$40-49$ & 59.9 & 13.5 & 15.6 & 11.0 & $3487(100.0)$ \\
Total & 42.3 & 12.7 & 23.4 & 21.5 & $16,739(100.0)$ \\
\hline
\end{tabular}

Table 3. Distribution of women respondents by house type and state.

\begin{tabular}{ccccc}
\hline \multirow{2}{*}{ Type of House } & \multicolumn{3}{c}{ States } & Total \\
\cline { 2 - 4 } & Assam & Manipur & Nagaland & \\
\hline Pucca & 8.6 & 2.2 & 8.2 & 7.0 \\
Semi pucca & 20.2 & 28.6 & 36.7 & 28.7 \\
Kaccha & 71.1 & 69.2 & 55.1 & 64.3 \\
& 6187 & 3841 & 6711 & 16,739 \\
Total & $(100.0)$ & $(100.0)$ & $(100.0)$ & $(100.0)$ \\
\hline
\end{tabular}

Table 4. Distribution of scheduled tribes and scheduled castes women by age at cohabitation and religion.

\begin{tabular}{ccccc}
\hline \multirow{2}{*}{$\begin{array}{c}\text { Age at Cohabitation } \\
\text { (in years) }\end{array}$} & \multicolumn{3}{c}{ Religion } & \multirow{2}{*}{ Total } \\
\cline { 2 - 4 } & Christian & Hindu & Others ${ }^{*}$ & \\
\hline Up to 15 & 5.5 & 12.4 & 10.6 & 8.0 \\
16 & 5.9 & 10.5 & 7.0 & 7.5 \\
17 & 8.6 & 10.1 & 7.5 & 9.1 \\
18 & 16.7 & 16.0 & 14.1 & 16.5 \\
19 & 10.4 & 10.8 & 10.6 & 10.5 \\
20 & 52.8 & 40.2 & 50.3 & 48.4 \\
& 10725 & 5815 & 199 & 16739 \\
Total & $(64.1)$ & $(34.7)$ & $(1.2)$ & $(100.0)$ \\
& $(100.0)$ & $(100.0)$ & $(100.0)$ & $(100.0)$ \\
\hline
\end{tabular}

*include Muslim, Buddhist, Sikh, etc. 
served among various religious groups in which Hindu women have reported having early cohabitation compared to Christian and other religious groups. These differences may be due to early marriages among the Hindus. It shows sexual experiences and encounter of sex early in lives. It is therefore suggested that HIV/AIDS campaign must be targeted to young girls and women regardless of their religious, tribal or non-tribal background. Since literacy rate is high among these women, it is suggested that educational institutions may be an appropriate starting point for communication.

\subsection{HIV/AIDS Awareness}

"Have you heard of an illness called HIV/AIDS"? This question was uniformly asked to all respondents. Figure 2 shows the association between awareness to HIV/AIDS to selected background characteristics. On the whole $59 \%$ women had heard of HIV/AIDS in all three states. Compared to rural areas the awareness is better in urban areas by $24 \%$ points. Further the figure shows that the women in the age group of $20-29$ years had heard most about HIV/AIDS (64\%) and least informed were in 40 44 years age group (51\%). The HIV/AIDS was no threat and unheard by these women twenty years ago when they were growing. It is not surprising that more urban women in the age group of $20-29$ years had heard of HIV/AIDS (85\%) than their rural counterpart (61\%) due to high electronic media exposure.

The awareness increases with increase in educational level. There are sharp differences of HIV/AIDS awareness between illiterate rural and literate urban women and the same for the women studied up to standard I - V in school. The rural illiterate women had heard least about HIV/AIDS whereas urban literate women had heard most about it. Improvement in educational opportunities for rural women may be the key to enhancing any information level including HIV/AIDS.

Broadly "economic status" of the women has been gauged with the help of their residential accommodation classified as pucca, semi-pucca and kaccha. There seems to be a positive association between degree of HIV/AIDS information and economic status of the respondents. Both rural and urban women living in pucca houses had known the most about HIV/AIDS (75\% and $85 \%$ ) as opposed to rural and urban living in kaccha houses $(49 \%$ and $73 \%$ ). As regard religious background of the respondent is concern it is found that Christians were better informed about HIV/AIDS compared to Hindus and other religious groups in both rural and urban areas.

Percentage share of women aware of HIV/AIDS is highest for Nagaland followed by Manipur and Assam (Figure 3). Education and religion might have been re-
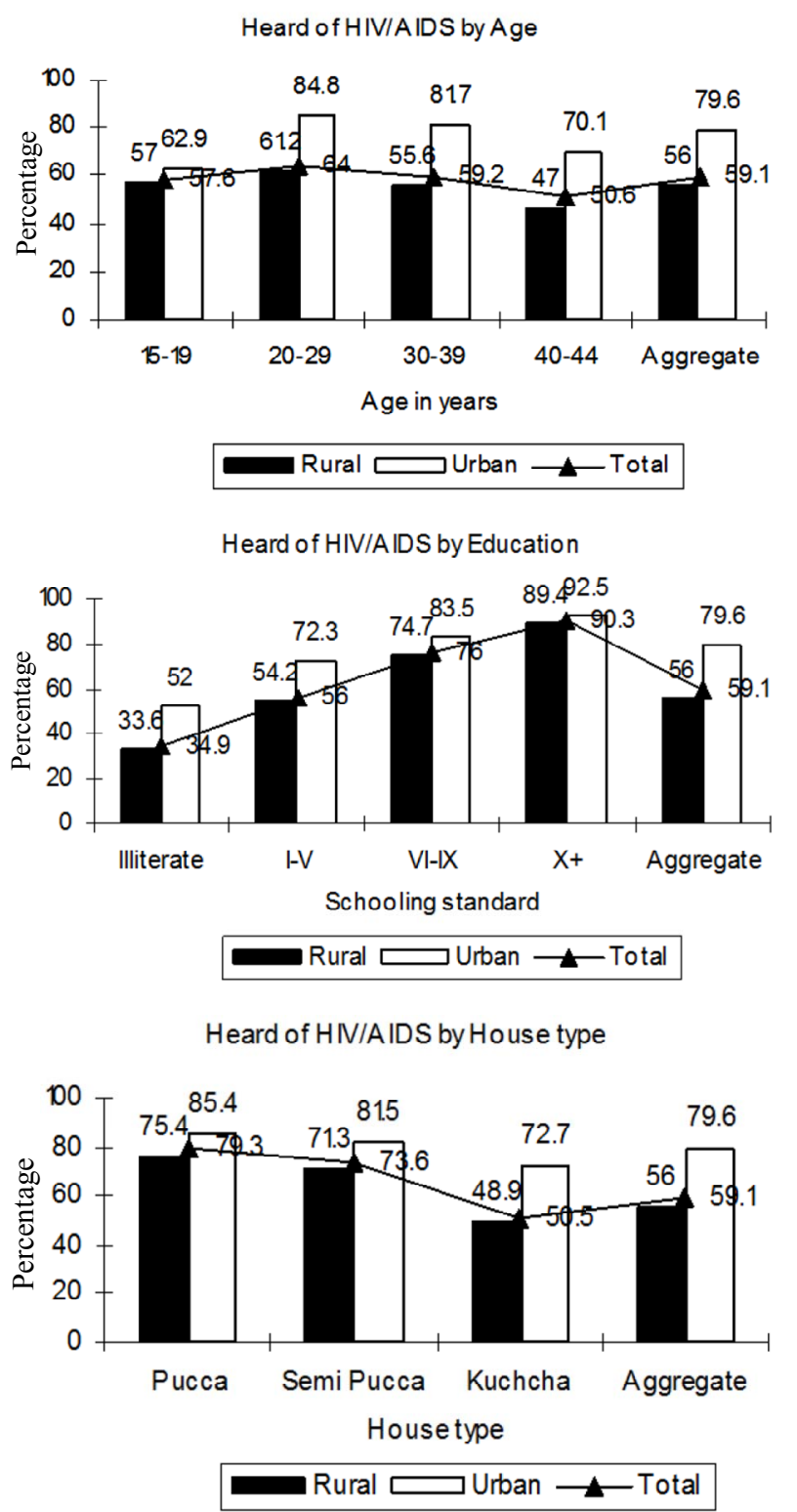

Heard of HIVIAIDS by Religion

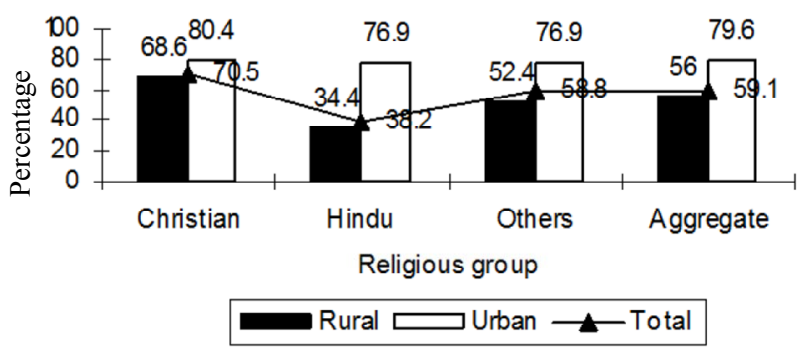

Figure 2. Aware of HIV/AIDS by background characteristics.

sponsible for such a differential level of HIV/AIDS information. 


\subsection{Sources of HIV/AIDS Information}

The respondents were asked to identify sources of information or persons from whom they had heard about HIV/ AIDS. For this purpose multiple information sources were indicated. Table 5 shows that both radio and television had provided maximum information to women in Assam (about 60\% each) and 60\% radio and $12 \%$ television in Manipur. In case of Nagaland, this figure is $56 \%$ radio and $32 \%$ television. It seems that radio user remain almost constant in the three states but the reach of television decreases as one moves from geographically accessible to inaccessible areas in northeastern region. Except Manipur print media (news paper, magazines and books) more or less gave an identical picture in providing information, though ability of print media to reach women was much lower than that of electronic media. Slo-

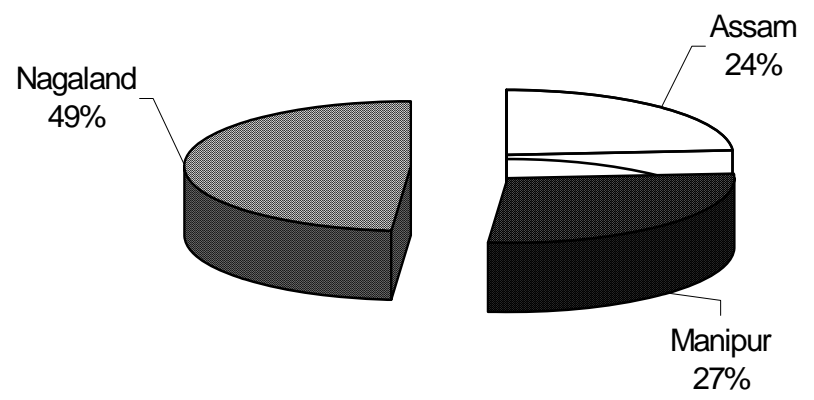

Figure 3. Percentage share of those who heard about HIV/ AIDS. gans/pamphlets and posters seemed quite effective in inaccessible states like Manipur (50\%) and Nagaland (36\%) of women came to know about HIV/AIDS through these means. Health workers including doctors had minor role in providing information about HIV/ AIDS. Community meeting and interpersonal communication among friends, relatives including husband remained another important source of information about HIV/AIDS in these states. In Nagaland, where $57 \%$ and $54 \%$ respondents reported having heard of HIV/AIDS through community meeting and inter-personal communication. The same for Manipur was $51 \%$ and $43 \%$ and for Assam it was 34\% and 51\% respectively. Other than radio, community meeting and inter-personal communication seems to be a dominant mode of sharing and exchanging information in inaccessible states like Nagaland and Manipur.

It is suggested that healthcare workers must not be utilized as prime movers and source of information of HIV/AIDS in northeastern region. Also state specific communication strategy should be designed to reach to women in their early age.

\subsection{Knowledge about Routes of Transmission of HIV/AIDS}

By and large a similar pattern of routes of transmission of HIV/AIDS was reported in all the age groups. Higher is the education; better is the reporting of all the means of transmission of HIV/AIDS. Over all Christian women

Table 5. Distribution of the respondents aware of HIV/AIDS by source of information.

\begin{tabular}{|c|c|c|c|c|c|c|c|c|c|c|}
\hline \multirow{3}{*}{ Sources of Information } & \multicolumn{9}{|c|}{ States } & \multirow{3}{*}{$\begin{array}{c}\text { Grand } \\
\text { Total }\end{array}$} \\
\hline & \multicolumn{3}{|c|}{ Assam } & \multicolumn{3}{|c|}{ Manipur } & \multicolumn{3}{|c|}{ Nagaland } & \\
\hline & Rural & Urban & Total & Rural & Urban & Total & Rural & Urban & Total & \\
\hline Radio & 61.0 & 57.5 & 60.5 & 59.2 & 71.0 & 60.2 & 49.9 & 51.9 & 50.4 & 55.5 \\
\hline $\mathrm{TV}$ & 55.0 & 88.3 & 60.1 & 9.8 & 38.8 & 12.1 & 24.3 & 45.4 & 29.5 & 32.1 \\
\hline News paper/Magazines & 39.5 & 56.1 & 42.1 & 13.2 & 37.4 & 15.1 & 30.9 & 49.8 & 35.6 & 31.5 \\
\hline Slogans/Pamphlet/Posters & 13.3 & 27.0 & 15.4 & 52.6 & 22.4 & 49.9 & 37.7 & 42.3 & 38.8 & 36.2 \\
\hline Doctors & 6.0 & 8.2 & 6.3 & 14.4 & 16.8 & 14.6 & 13.2 & 18.5 & 14.5 & 12.6 \\
\hline Health workers & 6.8 & 4.1 & 6.3 & 2.3 & 1.4 & 2.2 & 15.7 & 15.6 & 15.7 & 9.8 \\
\hline School teachers & 5.0 & 2.0 & 4.5 & 15.6 & 15.9 & 15.6 & 11.5 & 51.2 & 21.3 & 15.8 \\
\hline Community meeting & 36.6 & 17.2 & 33.6 & 52.5 & 31.8 & 50.9 & 76.4 & 56.7 & 71.5 & 56.8 \\
\hline Friends/Relatives husband & 52.0 & 46.0 & 51.1 & 41.8 & 52.3 & 42.6 & 64.1 & 51.2 & 60.9 & 53.6 \\
\hline \multirow{2}{*}{ Total } & 1999 & 367 & 2366 & 2490 & 214 & 2704 & 3630 & 1195 & 4825 & 9895 \\
\hline & $(100.0)$ & $(100.0)$ & $(100.0)$ & $(100.0)$ & $(100.0)$ & $(100.0)$ & $(100.0)$ & $(100.0)$ & $(100.0)$ & $(100.0)$ \\
\hline
\end{tabular}

*Percentages do not add up to 100 due to multiple responses. 
reported better than Hindus for different routes of transmission of HIV/AIDS (Table 6(a)). About $68 \%$ across three states believe that HIV/AIDS are transmitted through heterosexual sex. Pilot, et al. [10] in his study mentioned that hetro-sexual act is the main source of transmission of HIV/AIDS as it is estimated by them that at least $80 \%$ of all new cases of HIV infection in Africa are acquired heterosexually.

Further from the Table 6(a), it is evident that in contrast to Manipur and Nagaland a sizeable number of women $(40 \%)$ believe homosexual intercourse is also a means of transmission of the deadly infection. In another study conducted in southern India, it was highlighted that worldwide, about $75 \%$ of all HIV infections occur through sexual intercourse when one or other partner has HIV and the risk of spreading HIV greatly increased when other STDs are present [11]. Post in her article as available to us from internet reports that women are at greater risk of acquiring infection from an infected male partner and about 2 - 5 times higher than that of males of acquiring the infection from an infected female partner.

The use of common needle/blade or skin puncture was second most common mode by which HIV/AIDS infection is transmitted. This was most reported by women from Manipur. At this juncture it is to be mention that a study conducted by Sarkar [12] among the injectable drug user reports that in Manipur, HIV has spread with deadly speed among them.

Table 6. (a) Distribution of the respondents by routes of transmission and age, education and religion; (b) Distribution of the respondents by knowledge of routes of transmission and state.

(a)

\begin{tabular}{|c|c|c|c|c|c|c|c|c|c|c|c|}
\hline \multirow{2}{*}{ Routes of Transmission } & \multicolumn{4}{|c|}{ Age (in years) } & \multicolumn{4}{|c|}{ Education } & \multicolumn{3}{|c|}{ Religion } \\
\hline & $15-19$ & $20-29$ & $30-39$ & $40-44$ & Illiterate & $\mathrm{I}-\mathrm{V}$ & VI - IX & $\mathrm{X}+$ & Christian & Hindu & Others \\
\hline Male having sex with male (Homo sexual) & 16.0 & 27.2 & 26.8 & 29.4 & 16.6 & 22.6 & 27.0 & 36.0 & 35.4 & 18.8 & 24.7 \\
\hline Female having sex with male (Hetero sexual) & 69.5 & 65.2 & 68.2 & 59.8 & 56.2 & 60.5 & 67.7 & 79.6 & 61.1 & 73.5 & 69.4 \\
\hline Needles/blades/skin puncture & 47.9 & 55.4 & 54.6 & 52.6 & 39.5 & 47.2 & 54.1 & 69.0 & 45.7 & 57.3 & 56.9 \\
\hline Mother to child & 29.1 & 39.4 & 36.2 & 36.6 & 23.0 & 30.2 & 35.7 & 52.4 & 39.6 & 31.6 & 36.2 \\
\hline Blood transfusion & 44.1 & 51.4 & 48.2 & 42.2 & 32.4 & 38.3 & 50.3 & 63.5 & 41.6 & 49.6 & 50.7 \\
\hline Others & 0.5 & 1.5 & 1.6 & 1.8 & 1.1 & 1.8 & 2.0 & 1.8 & 1.1 & 2.6 & 1.7 \\
\hline Do not know & 24.4 & 18.3 & 18.6 & 21.4 & 31.6 & 24.2 & 18.7 & 8.1 & 30.1 & 12.0 & 16.3 \\
\hline & 213 & 3890 & 4028 & 1764 & 2471 & 1194 & 2979 & 3251 & 2219 & 117 & 7559 \\
\hline & $(100.0)$ & $(100.0)$ & $(100.0)$ & $(100.0)$ & $(100.0)$ & $(100.0)$ & $(100.0)$ & (100.0) & $(100.0)$ & $(100.0)$ & (100.0) \\
\hline
\end{tabular}

(b)

\begin{tabular}{|c|c|c|c|c|c|c|c|c|c|c|}
\hline \multirow{3}{*}{ Routes of transmission } & \multicolumn{9}{|c|}{ States } & \multirow{3}{*}{ Grand Total } \\
\hline & \multicolumn{3}{|c|}{ Assam } & \multicolumn{3}{|c|}{ Manipur } & \multicolumn{3}{|c|}{ Nagaland } & \\
\hline & Rural & Urban & Total & Rural & Urban & Total & Rural & Urban & Total & \\
\hline Male having sex with male (Homo sexual) & 37.5 & 56.2 & 40.1 & 8.4 & 27.6 & 10.4 & 28.5 & 34.9 & 30.1 & 27.1 \\
\hline Female having sex with male (Hetero sexual) & 58.4 & 80.4 & 61.8 & 76.1 & 88.3 & 77.0 & 67.5 & 61.5 & 66.0 & 68.0 \\
\hline Needles/blades/skin puncture & 39.3 & 56.7 & 42.0 & 59.7 & 81.8 & 61.5 & 54.6 & 63.2 & 56.7 & 54.5 \\
\hline Mother to child & 36.1 & 49.6 & 38.2 & 25.0 & 49.1 & 26.9 & 40.1 & 51.0 & 42.8 & 37.4 \\
\hline Blood transfusion & 35.2 & 51.5 & 37.7 & 45.3 & 69.6 & 47.2 & 53.0 & 61.6 & 55.1 & 48.8 \\
\hline Others & 1.3 & 1.1 & 1.2 & 0.8 & 2.3 & 0.9 & 1.7 & 3.4 & 2.2 & 1.6 \\
\hline Do not know & 33.3 & 11.7 & 30.0 & 19.3 & 7.9 & 18.4 & 16.4 & 7.6 & 14.2 & 19.1 \\
\hline \multirow{2}{*}{ Total } & 1999 & 367 & 2366 & 2490 & 214 & 2704 & 3630 & 1195 & 4825 & 9895 \\
\hline & $(100.0)$ & $(100.0)$ & $(100.0)$ & $(100.0)$ & $(100.0)$ & $(100.0)$ & $(100.0)$ & $(100.0)$ & $(100.0)$ & (100.0) \\
\hline
\end{tabular}

*Percentages do not add up to 100 due to multiple responses. 
The third important route for transmission of HIV/ AIDS as reported is due to blood transfusion (49\%). Belief that the infection is passed from mother to child was notable in the states of Assam and Nagaland (38\% and $43 \%$ respectively), but fairly low in Manipur (Table 6(b)). Shrotri et al. [13] in his study reports that northeastern SC/ST women were less aware of maternal to child infection than that SC/ST women residing in the western India.

The analysis shows inter-state and rural-urban differences in the knowledge thereby suggesting state specific communication strategy with special emphasis on rural areas to control HIV/AIDS spread in the region.

\subsection{Preventive Measures of HIV/AIDS}

Table 7 shows that by and large women were aware of different methods of HIV/AIDS control by varying degrees in three states. Safe sex/condom use in each intercourse seemed to be known to three-fourth of the women as sure means of HIV/AIDS prevention. Inter-state and rural urban variation were observed in the use of condom or safe sex as preventive measure, lowest being in Assam $(66 \%)$ and highest in Nagaland (78\%). To reveal the reality that in India a large number of women are not lucky to have husband who has a restrictive and positive outlook towards safer sex with his wife. On the contrary most of them believe that wife should share husbands sorrow more than joys may be it is biologically or socially destructive to her. Growing number of Indian women who have had sex only with their husbands are now being infected with HIV. A study conducted in the Pune district of Maharashtra state in Western India found that a good number of married women with STDs and none of whom reported sexual contacts outside their marriages were HIV positive [14]. Bhattacharya [15] in his study also stressed the use of condom among the heterosexual married couples in India towards prevention of HIV/AIDS infection.

About 49\% women knew that HIV/AIDS infection could be prevented by transfusion of tested blood. To be mentioned here that commercial blood donors are an integral part of Indian blood supply network and these donors are generally poor and tend to engage in high risk sex and intravenous drugs more than the general population. In a study conducted in $1992,86 \%$ of a group of commercial blood donors screened in Mumbai erstwhile Bombay were found to be HIV infected [16].

The use of sterilized needles and syringes could prevent infection is known to $52 \%$ women. However, only $28 \%$ knew that HIV/AIDS could be prevented by avoiding pregnancy among HIV/AIDS infected persons. About $22 \%$ of women did not know any preventive measures across three states. Both inter-state and rural-urban differences were observed in which a sizeable proportion of women in Assam (33\%) were not aware of any preventive measures against HIV/AIDS. It seems communication focus should be targeted towards actual preventive measures especially use of condom.

\subsection{Misconception about Mode of HIV/AIDS Transmission}

Little more than one-third of respondents had misconceptions as to how HIV/AIDS are transmitted among humans, highest being 42\% in Nagaland (Table 8(a)).

"Mosquito, flea or bed bug bites" was considered as one of the modes by which HIV/AIDS could be transmitted (25\%) followed by modes like "kissing" (21\%) and "sharing kitchen utensils and stepping on urine/stool

Table 7. Distribution of the respondents aware of preventive measure against HIV/AIDS by residence and state.

\begin{tabular}{|c|c|c|c|c|c|c|c|c|c|c|}
\hline \multirow{3}{*}{ Preventive measure } & \multicolumn{9}{|c|}{ States } & \multirow{3}{*}{ Grand Total } \\
\hline & \multicolumn{3}{|c|}{ Assam } & \multicolumn{3}{|c|}{ Manipur } & \multicolumn{3}{|c|}{ Nagaland } & \\
\hline & Rural & Urban & Total & Rural & Urban & Total & Rural & Urban & Total & \\
\hline Safe sex/Use of condom in each intercourse & 62.3 & 84.7 & 65.8 & 75.1 & 90.6 & 76.4 & 74.9 & 85.9 & 77.6 & 74.5 \\
\hline Check blood prior to transfusion & 38.2 & 56.1 & 41.0 & 45.7 & 70.1 & 47.7 & 51.9 & 62.4 & 54.5 & 49.4 \\
\hline Sterilize needles \& syringes for injection & 33.1 & 48.5 & 35.5 & 57.6 & 78.0 & 59.2 & 54.0 & 63.7 & 56.4 & 52.2 \\
\hline Avoid pregnancy when having AIDS & 24.1 & 34.1 & 25.7 & 19.8 & 38.8 & 21.3 & 33.2 & 31.2 & 32.7 & 27.9 \\
\hline Others & 1.2 & 0.5 & 1.1 & 0.7 & 1.9 & 0.8 & 1.6 & 2.4 & 1.8 & 1.3 \\
\hline Do not know & 36.4 & 13.9 & 32.9 & 20.7 & 7.5 & 19.7 & 19.5 & 9.0 & 16.9 & 21.5 \\
\hline \multirow{2}{*}{ Total } & 1999 & 367 & 2366 & 2490 & 214 & 2704 & 3630 & 1195 & 4825 & 9895 \\
\hline & $(100.0)$ & $(100.0)$ & (100.0) & $(100.0)$ & $(100.0)$ & $(100.0)$ & $(100.0)$ & $(100.0)$ & $(100.0)$ & (100.0) \\
\hline
\end{tabular}

*Percentages do not add up to 100 due to multiple responses. 
Table 8. (a) Distribution of the respondents having misconceptions about routes of transmission of HIV/AIDS by residence and state; (b) Distribution of the respondents having misconceptions about routes of transmission of HIV/AIDS by residence and state.

(a)

\begin{tabular}{|c|c|c|c|c|c|c|c|c|c|c|}
\hline \multirow{3}{*}{ Misconceptions } & \multicolumn{9}{|c|}{ States } & \multirow{3}{*}{$\begin{array}{c}\text { Grand } \\
\text { Total }\end{array}$} \\
\hline & \multicolumn{3}{|c|}{ Assam } & \multicolumn{3}{|c|}{ Meghalaya } & \multicolumn{3}{|c|}{ Nagaland } & \\
\hline & Rural & Urban & Total & Rural & Urban & Total & Rural & Urban & Total & \\
\hline Having misconception & 26.1 & 25.9 & 26.0 & 34.3 & 33.6 & 34.2 & 40.9 & 46.4 & 42.3 & 36.2 \\
\hline No misconception & 73.9 & 74.1 & 74.0 & 65.7 & 66.4 & 65.8 & 59.1 & 53.6 & 57.7 & 63.8 \\
\hline \multirow{2}{*}{ Total } & 1999 & 367 & 2366 & 2490 & 214 & 2704 & 3630 & 1195 & 4825 & 9895 \\
\hline & $(100.0)$ & $(100.0)$ & $(100.0)$ & $(100.0)$ & $(100.0)$ & $(100.0)$ & $(100.0)$ & $(100.0)$ & $(100.0)$ & $(100.0)$ \\
\hline
\end{tabular}

(b)

\begin{tabular}{|c|c|c|c|c|c|c|c|c|c|c|}
\hline \multirow{3}{*}{ Misconceptions } & \multicolumn{9}{|c|}{ States } & \multirow{3}{*}{$\begin{array}{c}\text { Grand } \\
\text { Total }\end{array}$} \\
\hline & \multicolumn{3}{|c|}{ Assam } & \multicolumn{3}{|c|}{ Meghalaya } & \multicolumn{3}{|c|}{ Nagaland } & \\
\hline & Rural & Urban & Total & Rural & Urban & Total & Rural & Urban & Total & \\
\hline Shaking hands & 5.0 & 3.0 & 4.6 & 5.3 & 4.7 & 5.3 & 12.3 & 14.0 & 12.7 & 8.7 \\
\hline Hugging & 9.0 & 7.4 & 8.7 & 6.3 & 7.9 & 6.5 & 15.4 & 14.6 & 15.2 & 11.3 \\
\hline Kissing & 19.3 & 16.9 & 18.9 & 13.8 & 11.2 & 13.6 & 26.4 & 25.7 & 26.3 & 21.1 \\
\hline Sharing cloths & 9.2 & 9.5 & 9.3 & 9.1 & 8.9 & 9.1 & 23.1 & 22.8 & 23.0 & 16.0 \\
\hline Sharing kitchen utensils & 9.8 & 9.2 & 9.7 & 10.5 & 8.4 & 10.3 & 26.1 & 26.4 & 26.2 & 17.9 \\
\hline Stepping on urine/stool & 6.9 & 7.9 & 7.1 & 11.8 & 10.3 & 11.7 & 26.3 & 26.8 & 26.4 & 17.8 \\
\hline Mosquito, flea or bedbug bites & 9.9 & 9.8 & 9.9 & 29.7 & 29.0 & 29.7 & 28.6 & 30.4 & 29.0 & 24.6 \\
\hline \multirow{2}{*}{ Total } & 1999 & 367 & 2366 & 2490 & 214 & 2704 & 3630 & 1195 & 4825 & 9895 \\
\hline & $(100.0)$ & $(100.0)$ & $(100.0)$ & $(100.0)$ & $(100.0)$ & $(100.0)$ & $(100.0)$ & $(100.0)$ & $(100.0)$ & $(100.0)$ \\
\hline
\end{tabular}

"Percentages do not add up to 100 due to multiple responses.

of HIV patient" (18\% each) (Table 8(b)). In the same order even "sharing cloths" (16\%) and hugging (11\%) believe to infect a person. It seems all known modes of transmissions related to other diseases were thought to be sources of HIV/AIDS infection though inter-state and rural-urban differences were observed. One of the surprising finding is that these misconceptions were higher among urban women than rural women in Nagaland, where as in the other two states it was almost similar in the two localities. In order to combat misconceptions, specific communication approach would be essential.

\subsection{Awareness to HIV/AIDS and Condom Use: A Multivariate Analysis}

Two separate multivariate logistic regression models are computed and results are presented in Table 9. Awareness to HIV/AIDS and ever use of condom are taken as dependent variables in the two models. Further aware- ness to HIV/AIDS is also taken as predictor in model-II. It is found that awareness to HIV/AIDS increases significantly with the increase in respondent's education. A similar pattern is observed in case of use of condom in model-II, but the relationship is not found significant. Husband's educational background is also found to be positively and significantly related to awareness to HIV/ AIDS and use of condoms. House type is also found to be positively and significantly associated with awareness to HIV/AIDS. Further the results shows that women living in kaccha houses had lower awareness compared to those living in pucca houses. However, no definite trend could be established for the same variable in case of use of condom. It is to be noted here that compared to Hindus, Christians were better aware of HIV/AIDS and the odds increases significantly. However, the use of condom was significantly lower among Christians compared to Hindus and other religious groups. Though Christians 
Table 9. Results of logistic regression showing the impact of background variables on respondent awareness on HIV/ AIDS and condom use.

\begin{tabular}{|c|c|c|}
\hline \multirow[b]{2}{*}{ Background variables } & \multicolumn{2}{|c|}{ Exponential $\beta$ for odds } \\
\hline & $\begin{array}{c}\text { Heard about of } \\
\text { HIV/AIDS (Model-I) }\end{array}$ & $\begin{array}{l}\text { Ever use of condom } \\
\text { (Model-II) }\end{array}$ \\
\hline \multicolumn{3}{|l|}{ Age of the respondents } \\
\hline $15-19^{R}$ & 1.000 & 1.000 \\
\hline $20-29$ & 1.114 & 1.376 \\
\hline $30-39$ & 1.200 & 1.828 \\
\hline $40-49$ & 0.988 & 1.281 \\
\hline \multicolumn{3}{|l|}{ Respondents education } \\
\hline Illiterate $^{\mathrm{R}}$ & 1.000 & 1.000 \\
\hline Class I - V & $1.944^{* * *}$ & 0.854 \\
\hline Class VI - IX & $3.721^{* * *}$ & 1.251 \\
\hline Class $\mathrm{X}+$ & $8.087^{* * *}$ & 1.190 \\
\hline \multicolumn{3}{|l|}{ Husband's education } \\
\hline Illiterate $^{\mathrm{R}}$ & 1.000 & 1.000 \\
\hline Class I - V & $1.380^{* * *}$ & 1.336 \\
\hline Class VI - IX & $1.965^{* * *}$ & $2.345^{* * *}$ \\
\hline Class $\mathrm{X}^{+}$ & $2.847^{* * *}$ & $3.661^{* * *}$ \\
\hline \multicolumn{3}{|l|}{ Type of house } \\
\hline Puccha $^{\mathrm{R}}$ & 1.000 & 1.000 \\
\hline Semi-puccha & 0.899 & 1.189 \\
\hline Kaccha & $0.619^{* * *}$ & 0.809 \\
\hline \multicolumn{3}{|l|}{ Religion } \\
\hline Hindu $^{R}$ & 1.000 & 1.000 \\
\hline Others & $2.758^{* * *}$ & $0.342^{* *}$ \\
\hline Christians & $4.260^{* * *}$ & $0.203^{* * *}$ \\
\hline \multicolumn{3}{|l|}{ Type of residence } \\
\hline Rural $^{R}$ & 1.000 & 1.000 \\
\hline Urban & $1.397^{* * *}$ & 1.124 \\
\hline \multicolumn{3}{|l|}{ Age at first cohabitation } \\
\hline Up to 17 years $^{R}$ & 1.000 & 1.000 \\
\hline 18 years + & 1.009 & $1.450^{* * *}$ \\
\hline \multicolumn{3}{|l|}{$\begin{array}{l}\text { Intention to use } \\
\text { condom in future }\end{array}$} \\
\hline Intend to use $\mathrm{e}^{\mathrm{R}}$ & 1.000 & 1.000 \\
\hline No intention & $0.065^{* *}$ & $0.173^{* * *}$ \\
\hline \multicolumn{3}{|l|}{ Awareness to HIV/AIDS } \\
\hline Aware $^{R}$ & & 1.000 \\
\hline Not aware & & $0.089^{* * *}$ \\
\hline
\end{tabular}

${ }^{* * *} \mathrm{P}<0.001,{ }^{* *} \mathrm{P}<0.01, \mathrm{R}$-refers to reference category. were better aware of HIV/AIDS than others but they need special motivation towards the use of condom. Urban women were significantly better aware of HIV/AIDS and they were also found to have use condoms more than their rural counterpart, the results are not significant in model-II. The legal age at marriage in India for women is 18 years. Due to lower age at marriage in India co-habitation usually takes place at a very tender age. It is found that those who co-habit for the first time at the age of 18 years or above were better aware of HIV/AIDS. Also they are better user of condoms compared to those who first cohabit below 18 years. Thus communication strategy must stress to raise the age at marriage. The results also indicates that those who do not intend to use condom in future were significantly lesser aware of HIV/ AIDS compared to those who intend to use condom in future. Further it is also seen that intention for condom use in future has a significant and positive linkage with ever use of condom. Further those who were not aware of HIV/AIDS were significantly lesser users of condoms. This positive relationship between AIDS knowledge and condom use was also found among African women [17]. Need of the hour is to motivate people and promote condom use as a safeguard against the dreaded infection.

\section{Conclusions and Suggestions}

The study reveals that about $59 \%$ women had heard of HIV/AIDS in all the three states. The age share of those who heard about HIV/AIDS is the highest among Nagaland (49\%) followed by Manipur (27\%) and Assam (24\%). Thus communication strategies should pay more attention to the later two states. Radio appears to be more popular than television. Electronic media particularly television reach decreases as one moves from geographically accessible areas to inaccessible areas in northeastern region. Except for Manipur, the print media more or less gave an identical picture in providing information. Slogans/pamphlets and posters seemed quite effective in accessible areas. About $68 \%$ believe that HIV/AIDS are transmitted through heterosexual act. However, there are inter-state differences in the knowledge suggesting state specific communication strategy. "Safe sex/use of condom to prevent HIV/AIDS" seemed to be known to $75 \%$ women as a sure means of HIV/ AIDS prevention. Almost one third of respondents had misconception as to how HIV/AIDS is transmitted among human beings. So it is urgently felt to develop intra-region specific communication approach, female focused communication and emphasis on inter-personal communication. Furthermore, the multivariate analysis suggests that respondents' education, their husbands' educational background and their economic condition are significantly and positively associated towards awareness to 
HIV/AIDS. The multivariate model also suggests that husbands' education of respondents plays a pivotal role in determining the use of condom - a strong preventive measure against HIV/AIDS and thus it demands to increase men's participation in reproductive health matters. The analysis also shows that though Christians are better aware of HIV/AIDS, the use of condom among them is lower than Hindus.

Manipur and Nagaland have predominantly Christian population, whereas Assam has Hindu population. A comparison of the responses of Christian and Hindu respondents has been made for evolving broad communication strategy in northeastern region of India. The suggested communication strategies are mentioned below.

\subsection{Need for Region Specific Communication Approach}

Inter-state and rural-urban differences were observed about HIV/AIDS awareness, prevention methods, media contribution and related misconceptions about HIV/ AIDS among three states. Hence, communication approach must take these findings and findings of similar surveys in other northeastern states into consideration while designing any communication strategy. Education seems to be the single most important determinant in creating awareness of HIV/AIDS. Communication of HIV/AIDS message should aim at reducing the existing knowledge gap and bring about desired behavioural changes among the persons considered in "high risk" group with special reference to female population of Scheduled caste and Scheduled tribes in northeastern region. Two specific communication approaches have been suggested to develop state and community specific communication strategy.

\subsection{Female Focused Communication}

Keeping in view that women by and large in northeastern region play a prominent role in domestic and community activities, a "female focused" communication will have positive effects in controlling HIV/AIDS in the region. The women should be "educated" to remove the misconception, and to persuade their men folks to adopt methods of safe sex. The "safe sex" concept must be incorporated in the family planning programme and media message must highlight concept of safe sex. Since women encounter sexual experiences early in their lives, existing means of communication including educational institutions must form a part of an "advocacy group" to promote safe sex targeted to young and adolescent females women who should be encouraged to persuade their men folks to use condom for safe sex and sex denial to men without condom use should be advocated. A study suggested the promotion of condom use particularly in the context of casual sexual relations to reduce the potential for the spread of STD/HIV in Bangladeshi population [18]. At the same time, communication should also stress to raise the age at marriage in the region.

\subsection{Emphasis on Interpersonal Communication}

In all three states' interpersonal communication, husbands and other relatives seem to provide a great deal of information to women. Due to limited reach of mass media in inaccessible areas, interpersonal communication keeps a prime mode of sharing and exchanging views of ideas. Also community meetings are found to be effective in these areas. Hence, it is suggested that apart from electronic and print media, interpersonal communication, community meetings and use of posters, hoarding and other existing locally popular means must form an integral part of communication strategy. Efforts should be made to utilize health workers including doctors in creating awareness of HIV/AIDS who are currently least involved in promoting health care.

\section{Acknowledgements}

The authors sincerely acknowledge the support extended by Dr. Neeru Singh, Director, Regional Medical Research Centre for Tribals (ICMR), Jabalpur and Indian Council of Medical Research, New Delhi, India for providing the facilities. Further the authors also place on record and thank Ministry of Health and Family Welfare, Government of India and International Institute for Population Sciences, Mumbai, India for allowing using RCH data set for the study.

\section{REFERENCES}

[1] J. Shreedhar and A. Colaco, "Broadening the Front: NGO Response to HIV and AIDS in India," ACTIONAID, The British Council, New Delhi, 1996.

[2] UNAIDS/NACO/WHO, "2.5 Million People Living in India with HIV, According to New Estimates," Statistics on HIV/AIDS Cases India 2005-2006, 2007.

[3] NACO, "Monthly Updates on AIDS, NACO, India, $31^{\text {st }}$ August," Statistics on HIV/AIDS Cases India 2005-2006, 2006.

[4] G. Thomas, "AIDS in India," Rawat Publication, Jaipur, 1994.

[5] H. C. Srivastava, K. B. Saha and K. I. Sahay, "Understanding Awareness and Knowledge about AIDS in the Selected States of India," XXI Annual Conference of Indian Association for Studies in Population, Banaras Hindu University, 1998, Unpublished.

[6] J. Moore, "AIDS: Prevention and Control. Invited Presentations and Papers from the World Summit of Ministers 
of Health on Programmes for AIDS Prevention," World Health Organization, Geneva, Pergomoo Press, Oxford, 1988.

[7] IIPS, "Reproductive and Child Health Project-Rapid Household Survey," Phase I and II (1998-99) for Assam, TALEEM Research Foundation, Ahmedabad and International Institute for Population Sciences, Mumbai, 2001

[8] IIPS, "Reproductive and Child Health Project-Rapid household Survey," Phase I and II (1998-99) for Manipur, International Institute for Population Sciences, Mumbai, 2001.

[9] IIPS, "Reproductive and Child Health Project-Rapid Household Survey," Phase I and II (1998-99) for Nagaland, TALEEM Research Foundation, Ahmedabad and International Institute for Population Sciences, Mumbai, 2001.

[10] P. Pilot, B. M. Kapita, E. N. Ngugi, J. M. Mann, R. Colebunders and R. Wabitsch, "AIDS in Africa-A Manual for Physicians," WHO, Geneva, 1992.

[11] S. Solomon, "Personal Communication," c.f. Shreedhar and Colaco op cit, 1995.

[12] S. Sarkar, "HIV Due to Injecting Drug Use-A Special Focus in India," Indian Council of Medical Research, AIDS Unit, 1995, Unpublished.

[13] A. Shrotri, A. V. Shankar, S. Sutar, A. Joshi, N. Suryawanshi, H. Pisal, K. E. Bharucha, M. A. Phadke, R. C. Bollerger and J. Sastry, "Awareness of HIV/AIDS and Household Environment of Pregnant Women in Pune, India," International Journal of STD and AIDS, Vol. 14, No.
12, 2003, pp. 835-839. http://dx.doi.org/10.1258/095646203322556183

[14] J. J. Rodrigues S. M. Mehendale, M. E. Shepherd, A. D. Divekar, R. R. Gangakhedkar, T. C. Quinn, R. S. Paranjape, A. R. Risbud, R. S. Brooknoyer and D. A. Gadkari, "Risk Factors for HIV Infection in People Attending Clinics for Sexually Transmitted Diseases in India," British Medical Journal, Vol. 311, No. 7000, 1995, pp. 283286. http://dx.doi.org/10.1136/bmj.311.7000.283

[15] G. Bhattacharya, "Socio-Cultural \& Behavioural Contexts of Condom Use in Heterosexual Married Couples in India: Challenges to the HIV Prevention Program," Health Education and Behaviour, Vol. 31, No. 1, 2004, pp. 101117. http://dx.doi.org/10.1177/1090198103259204

[16] G. V. Bhimani and I. S. Gilada, "HIV Prevalence in People with no Fixed Abode-A Study of Blood Donorship Pattern and Risk Determinants," VIII International Conference on AIDS, Amsterdam, 1992, c.f. abstract \# Moc 0093. http://www.indianchild.com/aids in india.htm

[17] S. L. Zellner, "Condom Use and the Accuracy of AIDS Knowledge in CÔLE d' IVOIRE," International Family Planning Perspective, Vol. 29, No. 1, 2003, pp. 41-47. http://dx.doi.org/10.2307/3181000

[18] L. Gibney, N. Saquib and J. Metzger, "Behavioural Risk Factors for STD/HIV Transmission in Bangladesh's Trucking Industry," Social Science \& Medicine, Vol. 56, No. 7, 2003, pp. 1411-1424. http://dx.doi.org/10.1016/S0277-9536(02)00138-7

\section{List of Abbreviations}

\section{Abbreviation/Symbol Meaning:}

HIV: Human immunodeficiency syndrome

AIDS: Acquired immune deficiency syndrome

$\%$ : Percent 